\title{
$1 \quad$ Alkane and wax ester production from lignin derived molecules
}

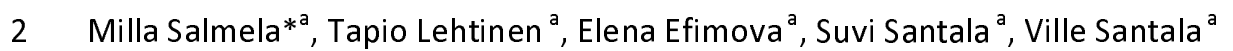

$3{ }^{a}$ Laboratory of Chemistry and Bioengineering, Tampere University of Technology, Korkeakoulunkatu

48 8, 33720 Tampere, Finland

$5 \quad *$ Corresponding author

6 Funding: Academy of Finland, grant no. 310135, 310188, 311986

\section{Abstract}

8 Lignin has potential as a sustainable feedstock for microbial production of industrially relevant

9 molecules. However, the required lignin depolymerization yields a heterogenic mixture of aromatic

10 monomers that are challenging substrates for the microorganisms commonly used in industry. Here,

11 we investigated the properties of lignin-derived molecules (LDMs), namely coumarate, ferulate, and

12 caffeate, in the synthesis of biomass and products in a LDM-utilizing bacterial host Acinetobacter

13 baylyi ADP1. The biosynthesis products, wax esters and alkanes, are relevant compounds for the

14 chemical and fuel industries. In A. baylyi ADP1, wax esters are produced by a native pathway,

15 whereas alkanes are produced by a synthetic pathway introduced to the host. Using individual LDMs

16 as substrates, the growth, product formation, and toxicity to cells were monitored with internal

17 biosensors. Of the tested LDMs, coumarate was the most propitious in terms of product synthesis.

18 Wax esters were produced from coumarate with a yield and titer of $40 \mathrm{mg} / \mathrm{g}_{\text {coumarate }}$ and $221 \mathrm{mg} / \mathrm{L}$,

19 whereas alkanes were produced with a yield of $62.3 \mu \mathrm{g} / \mathrm{g}_{\text {coumarate }}$ and titer of $152 \mu \mathrm{g} / \mathrm{L}$. This study

20 demonstrates the microbial preference for certain LDMs, and highlights the potential of $A$. baylyi

21 ADP1 as a convenient host for LDM upgrading to value-added products.

22 Key words: Lignin, alkane, wax ester, Acinetobacter baylyi ADP1

\section{Introduction}


Microbial processes utilizing non-edible biomass as a substrate can offer a sustainable solution for the production of fuels and chemicals. Comprehensive utilization of cheap waste streams obtained from agriculture and forest industry, could improve the economic viability of the bioprocesses (FitzPatrick et al., 2010), (Elshahed, 2010), (Clark et al., 2006), (Steen et al., 2010)(Peralta-Yahya et al., 2012). Currently lignin, one of the most abundant biopolymers, is underutilized mainly due to its recalcitrance and heterogeneity. Because of the complex structure, feedstock originating from lignocellulose and lignin treatment processes contain a heterogeneous mixture of compounds, including phenols, acids and residual sugars (Katahira et al., 2016)(Constant et al., 2016)(Abdelkafi et al., 2011)(Sun et al., 2015)(Li et al., 2012) (Karp et al., 2016) (Raj et al., 2007). Many lignin-derived molecules (LDMs) are growth inhibitors poorly tolerated by the most commonly used microbial production hosts, such as Escherichia coli and Saccharomyces cerevisiae. (Rumbold et al., 2009)(Sun et al., 2001)(Palmqvist and Hahn-Hägerdal, 2000)(Jönsson and Martín, 2016)(Adeboye et al., 2014). More importantly, these strains lack the catabolic pathways for LDM utilization. Thus, increasing attention is given towards microbial hosts that are capable of tolerating and metabolizing the LDMs, and can be employed as modular cell factories for the synthesis of products of interest (Nielsen et al., 2009)(Freed et al., 2018).

Acinetobacter baylyi ADP1 is an example of a wide substrate range bacterium that can degrade and utilize LDMs for growth and biosynthetic pathways. In A. baylyi ADP1, aromatic compounds are channeled to the central metabolism via a $\beta$-ketoadiapate pathway (Bleichrodt et al., 2010) . In this upper funneling pathway, structurally different compounds are converted to central intermediates, protocatechuate or catechol, before entering the $\beta$-ketoadiapate pathway and eventually resulting in common metabolites acetyl-CoA and succinyl-CoA (Ornston, 1966)(Fuchs et al., 2011) (Fischer et al., 2008). Thus, the $\beta$-ketoadiapate pathway could be exploited in the synthesis of a broad range of acetyl-CoA derived compounds from lignin-derived feedstock. Previous demonstrations of microbial upgrading of LDMs include the production of medium-chain $\left(\mathrm{C}_{6}-\mathrm{C}_{14}\right)$ polyhydroxyalkanoates $(\mathrm{PHA})$ by Pseudomonas putida (Linger et al., 2014) and triacylglycerols by Rhodococcus opacus (Kosa and 
Ragauskas, 2012). Lignin-derived phenolic compounds such as coumarate, ferulate and caffeate are structural analogues metabolized through the protocatechuate branch of the upper funnelling pathway (Fischer et al., 2008). The occurrence and position of substitution groups in the aromatic ring may affect the biochemical reactions and inhibitory effects of these compounds. On the other hand, the diversity of phenolic compounds released from biomass depends on the chosen pretreatment method and the origin of the biomass (Constant et al., 2016). Thus, studies on the substrate preferences of the microbial cell factories promotes preferable choice of biomass and pretreatment methods.

In addition to LDM utilization, A. baylyi ADP1 has interesting features of being readily genetically engineered organism (Metzgar, 2004) (Elliott and Neidle, 2011) (de Berardinis et al., 2008) that also accumulates industrially relevant long-chain alkyl esters (wax esters). Similarly to other storage lipids, wax esters are produced intracellularly in nitrogen-deficient conditions with excess carbon reserves (Alvarez and Steinbüchel, 2003)(Fixter et al., 1986)(Santala et al., 2014). The wax esters produced by A. baylyi ADP1 resemble the structure of jojoba-oil (produced by Simmondsia chinensis) with a typical carbon content of $\mathrm{C}_{32}-\mathrm{C}_{36}$ (Fixter et al., 1986)(Kalscheuer and Steinbüchel 2003) (Lehtinen et al., 2018a), The composition of wax esters can be modified by alternating process conditions (Dewitt et al., 1982) or by genetically rewiring pathways (Santala et al. 2014), presenting further opportunities in product tailoring. On the other hand, genome integrated synthetic pathways provide practical means to produce non-native products of industrial relevance. For example, we have previously constructed an $A$. baylyi ADP1 strain that accumulates intracellular alkanes by expressing a non-native fatty acid reductase (AAR) and an aldehyde deformylating oxygenase (ADO) (Lehtinen et al., 2017b). In the strain, the naturally occurring alkane degradation and wax ester synthesis pathways of $A$. baylyi ADP1 were disrupted by targeted gene knock-outs and an optimized alkane production pathway was integrated (Lehtinen et al., 2017b). Microbial wax esters and alkanes have previously been produced using carbon sources such as glucose and organic acids (Kannisto et 
al., 2014) (Lehtinen et al., 2018a)(Salmela et al., 2018a) (Santala et al., 2011) (Schirmer et al.,

2010)(Lehtinen et al., 2017b)(Cao et al., 2016) (Fatma et al., 2018)(Lehtinen et al., 2017a).

Here, we demonstrate the production of wax esters $\left(C_{32-34}\right)$ and alkanes $\left(C_{17}\right)$ by $A$. baylyi ADP1 from

\section{Strains, media and components}

A. baylyi ADP1 'sensor-strain' (Santala et al. 2011) -designated here as the wax ester producing WP strain - was used for internal aldehyde monitoring and wax ester production. The WP strain originates from the wild type strain A. baylyi ADP1 (DSM 24193) with a bacterial luciferase gene iluxAB replacing gene poxB (ACIAD3381) associated with pyruvate dehydrogenase activity. The WP strain genotype is $A$. baylyi ADP1 $100 \times B:: I u x A B, \mathrm{~cm}^{r}$. A biosensor strain originating from the same wild type modified to produce alkanes instead of wax esters (Lehtinen et al. 2017a) - designated as the alkane producing AP strain - was used for internal aldehyde and alkane monitoring, and alkane production. In this strain, the gene encoding native alkane degrading activity (AlkM) of $A$. baylyi has been replaced by GFP-gene under a native alkane inducible promoter. Additionally, it has two nonnative genes aar (acyl-acyl carrier protein (ACP) reductase) and ado (aldehyde-deformylating oxygenase) from Synechococcus elongates integrated in the genome replacing a putative prophage segment (pp2), to allow alkane synthesis. The gene expression from this synthetic alkane-producing pathway is controlled by Lacl and isopropyl $\beta$-D-1-thiogalactopyranoside (IPTG) inducible promoter. 
100 Furthermore, the strain AP has the genes ACIAD3383-3381 knocked-out and replaced by the

101 bacterial luciferase genes /uxAB. The ACIAD3383 (acr1) is associated with reduction of fatty acyl-CoA,

102 thus its elimination removes the native long chain fatty aldehyde production related to the wax ester

103 production. The genotype of AP strain is A. baylyi

104 ADP1 $\Delta p o x B \Delta m e t Y \Delta a c r 1:: / u x A B, \mathrm{~cm}^{r} \Delta a l k M:: s f g f p, \operatorname{kan}^{r} \Delta p p 2:: a a r, a d o, \mathrm{spc}^{r}$.

105

106

All cultivations were done in mineral salts media (Hartman et al. 1989) with some modifications $\left(\mathrm{K}_{2} \mathrm{HPO}_{4} 3.88 \mathrm{~g} / \mathrm{L}, \mathrm{NaH}_{2} \mathrm{PO}_{4} 1.63 \mathrm{~g} / \mathrm{L},\left(\mathrm{NH}_{4}\right)_{2} \mathrm{SO}_{4} 2.00 \mathrm{~g} / \mathrm{L}, \mathrm{MgCl}_{2} .6 \mathrm{H}_{2} \mathrm{O} 0.1 \mathrm{~g} / \mathrm{L}\right.$, EDTA $10 \mathrm{mg} / \mathrm{L}$, $\mathrm{ZnSO}_{4} .7 \mathrm{H}_{2} \mathrm{O} 2 \mathrm{mg} / \mathrm{L}, \mathrm{CaCl}_{2} \cdot 2 \mathrm{H}_{2} \mathrm{O} 1 \mathrm{mg} / \mathrm{L}, \mathrm{FeSO}_{4} .7 \mathrm{H}_{2} \mathrm{O} 5 \mathrm{mg} / \mathrm{L}, \mathrm{Na}_{2} \mathrm{MoO}_{4} \cdot 2 \mathrm{H}_{2} \mathrm{O} 0.2 \mathrm{mg} / \mathrm{L}, \mathrm{CuSO}_{4} .5 \mathrm{H}_{2} \mathrm{O} 0.2$ $\mathrm{mg} / \mathrm{L}, \mathrm{CoCl}_{2} \cdot 6 \mathrm{H}_{2} \mathrm{O} 0.4 \mathrm{mg} / \mathrm{L}, \mathrm{MnCl}_{2} \cdot 2 \mathrm{H}_{2} \mathrm{O} 1 \mathrm{mg} / \mathrm{L}$ ) supplemented with $0.2 \%$ casein amino acids and antibiotics when required (kananmycin $50 \mu \mathrm{g} / \mu \mathrm{L})$. Sodium acetate $(25 \mathrm{mM})$ and coumarate, ferulate, or caffeate $(15 \mathrm{mM})$ were used as carbon sources if not stated otherwise. IPTG $(100 \mu \mathrm{M})$ (ThermoFisher, USA) was used for induction of the alkane production. All analytical compounds were purchased either form Sigma (USA) or Tokyo chemical industries (Japan).

\section{Comparison of different LDMs as carbon source}

Growth and fatty aldehyde formation of the wax ester producing WP strain and the AP strain were measured on 96-well plates (Greiner Bio-one, Austria). The cells were incubated in a total volume of $200 \mu \mathrm{L}$ and supplemented with $25 \mathrm{mM}$ of acetate and either $15 \mathrm{mM}$ of coumarate, ferulate, or caffeate. Cultivations supplemented with either $25 \mathrm{mM}$ acetate or $0.2 \%$ casein amino acids were used as control cultivations. The cells were cultivated in Spark microplate reader (Tecan, Switzerland) at $30^{\circ} \mathrm{C}$ for 30 hours. Luminescence and optical density (OD) at $600 \mathrm{~nm}$ were measured at $30 \mathrm{~min}$ intervals and the plate was shaken for $5 \mathrm{~min}$ before reading (108 rpm, $2.5 \mathrm{~mm}$ amplitude). Additionally, luminescence and fluorescence signals (excitation $485 \pm 10 \mathrm{~nm}$, emission $510 \pm 5 \mathrm{~nm}$ ) were measured from the AP strain. The fluorescence signal was divided by the maximum $\mathrm{OD}_{600}$ value to indicate produced alkanes per biomass. Media supplemented with the corresponding carbon source without inoculant were used as blanks and the background signal was subtracted from the 
obtained sample values. All cultivations were conducted in triplicates. The AP strain was induced with $100 \mu \mathrm{M}$ IPTG and supplemented with kanamycin $(50 \mu \mathrm{g} / \mathrm{mL})$. Similar setup was used for studying substrate toxicity with the WP strain except that acetate (25-200 mM) and coumarate (13$120 \mathrm{mM}$ ) mixtures of various concentrations were used as carbon sources in $48 \mathrm{~h}$ cultivations.

\section{Alkane and wax ester production from coumarate in $50 \mathrm{ml}$ batch cultures}

The WP and AP strains were grown on $25 \mathrm{mM}$ acetate and $15 \mathrm{mM}$ coumarate for 24 hours in a total volume of $50 \mathrm{~mL}$ in $250 \mathrm{ml}$ flasks at $30^{\circ} \mathrm{C}$ and $300 \mathrm{rpm}$. Samples for analyses were collected after 8 , 12 and $24 \mathrm{~h}$ of cultivation. Acetate and coumarate concentrations were measured with HPLC and cell growth (OD) was measured with spectrophotometer at $600 \mathrm{~nm}$. Alkanes and wax esters were analyzed from extracted lipids with thin layer chromatography (TLC) (wax esters) or gas chromatography-mass spectrometry (GC-MS) (alkanes) as described in analytical methods. Control cultivations contained $0.2 \%$ casein amino acids or $0.2 \%$ casein amino acids and $25 \mathrm{mM}$ acetate. All cultivations were done as triplicates. The $\mathrm{C} / \mathrm{C}$ yield was calculated by dividing the carbon content of heptadecane with the carbon content of the substrates (acetate and coumarate) after subtracting the titer from the casein amino acid control cultivation. Similarly, the yield was calculated as $\mathrm{g} / \mathrm{g}_{\text {coumarate }}$ consumed after subtracting the titer from the acetate control cultivation.

\section{Wax ester production from coumarate in 1-L bioreactor}

Larger scale bioreactor experiment was conducted with the WP strain in a 1-liter reactor (Sartorius Biostat $\mathrm{B}$ plus Twin System, Germany) with an online $\mathrm{pH}$ and $\mathrm{pO}_{2}$ monitoring system and automated $\mathrm{O}_{2}$ feed. An initial media volume of $750 \mathrm{ml}$ was supplemented with $25 \mathrm{mM}$ of acetate and $15 \mathrm{mM}$ coumarate and inoculated with the WP strain pre-cultivated in $100 \mathrm{mM}$ acetate, the initial OD being 0.14. Temperature was set to $30{ }^{\circ} \mathrm{C}$ and stirring to $300 \mathrm{rpm}$. Samples were collected periodically either as $50 \mathrm{ml}$ (for NMR, CDW, HPLC measurements) or as $5 \mathrm{ml}$ (HPLC and OD measurements). Coumarate was supplemented to the reactor after carbon depletion in a total volume of $20 \mathrm{ml}$ in concentrations of either $24.5 \mathrm{mM}$ or $34.5 \mathrm{mM}$. The $\mathrm{mg} / \mathrm{g}$ yield for wax esters were calculated with 
150 an average chain length of 34 carbons $(506 \mathrm{~g} / \mathrm{mol})$ (Lehtinen et al., 2018b) from the $34.5 \mathrm{mM}$

151 coumarate supplementation.

\section{Analytical methods}

Acetate, coumarate and 4-HBA concentrations were measured with HPLC (Agilent 1100 series, HewlettPackard, Germany) equipped with Fast acid H+ column (Phenomex, USA), a degasser (G1322A) and an UV-detector (G1315A) using $0.005 \mathrm{~N} \mathrm{H}_{2} \mathrm{SO}_{4}$ as eluent. The pump (G1211A) flow was adjusted to $1 \mathrm{ml} / \mathrm{min}$, the column temperature to $80^{\circ} \mathrm{C}$, and peaks were identified at wavelength $310 \mathrm{~nm}$ for coumarate and $210 \mathrm{~nm}$ for acetate and 4-HBA by comparing the retention times and spectral profiles to prepared standards.

Wax esters and alkanes were extracted from cells by methanol-chloroform extraction as described previously (Santala et al., 2011): extraction was conducted for cell pellets obtained by centrifugation (12 $000 \mathrm{~g} \times 5 \mathrm{~min}$ ) from equal volumes of cell cultures $(12 \mathrm{ml})$. The cell pellets were suspended in methanol $(500 \mu \mathrm{l})$, chloroform was added $(250 \mu \mathrm{l})$, and the samples were incubated at room temperature with gentle mixing for 1 hour. Thereafter, chloroform $(250 \mu \mathrm{l})$ and PBS $(250 \mu \mathrm{l})$ were added, and the gentle mixing was continued for two more hours. Finally, the samples were centrifuged and the lower phase (chloroform) was used for analyses.

Thin layer chromatography (TLC) analysis was carried out with $10 \times 10 \mathrm{~cm}$ HPTLC Silica Gel 60 F254 glass plates with $2.5 \times 10 \mathrm{~cm}$ concentrating zone (Merck, USA). Extracted samples were loaded on the plate $(30 \mu \mathrm{l})$ and jojoba-oil was used as a standard for wax esters. The mobile phase consisted of n-hexane:diethylether:acetic acid (90:15:1). For visualization, the plate was stained with iodine. Alkanes were measured with GC-MS (Agilent Technologies 6890N/5975B) equipped with HP-5MS $30 \mathrm{~m} \times 0.25 \mathrm{~mm}$ column with $0.25 \mu \mathrm{m}$ film thickness. Helium flow rate was adjusted to $4.7 \mathrm{ml} / \mathrm{min}$ and a $1 \mu \mathrm{l}$ splitless injection was used. The oven program was adjusted to $55^{\circ} \mathrm{C}$ hold $5 \mathrm{~min}, 55-$ $280^{\circ} \mathrm{C} 20^{\circ} / \mathrm{min}$ ramp and $280^{\circ} \mathrm{C}$ hold $3 \mathrm{~min}$. Scanning occurred at $50-500 \mathrm{~m} / \mathrm{z}, 1.68 \mathrm{scan} / \mathrm{s}$. Chromatograph peaks were identified based on the NIST library (Version 2.2/Jun 2014) and on 
heptadecane external standards (Sigma-Aldrich, USA). The accumulation of 8-heptadecene was

determined only qualitatively by comparing the chromatograph peaks within the samples and to the

GC library as a standard compound was not commercially available.

NMR was used for quantitative wax ester analysis as described by Santala et al. (2011). Briefly,

alkoxy methylene protons of ester bonds that are specific to wax esters.

\section{Results and Discussion}

A. baylyi ADP1 belongs to a bacterial species capable of metabolizing a variety of aromatic

compounds by enzymatically funneling them towards central intermediates. The compounds are

metabolized via the $\beta$-ketoadiapate pathway to succinyl-CoA and acetyl-CoA (Wells and Ragauskas,

2012). As the latter is an essential intermediate for the synthesis of fatty-acid derived products, such

as the naturally produced wax esters in A. baylyi (Reiser and Somerville, 1997), (Stöveken and 
200

201

202

203

204

205

206

207

synthesis pathway (Lehtinen et al., 2018a; Santala et al., 2011). The second strain, designated here as 'AP', is engineered for the synthesis of alkanes by a non-native pathway, and contains a sensor system for the detection of both aldehydes (a precursor in alkane synthesis) monitored via bioluminescence, and alkanes, detected as fluorescence (Lehtinen et al., 2017b). To avoid degradation of the produced alkanes or direction of acetyl-CoA to wax esters instead of alkanes, the native alkane-degrading pathway and the wax ester synthesis pathway of $A$. baylyi ADP1 have been disrupted. The proposed carbon flow from substrate to product in the strains WP and AP is presented in Figure 1.

\section{Product synthesis and biomass from LDM representatives}

The WP and AP strains were employed to study the potential of coumarate, ferulate and caffeate as carbon sources for simultaneous product synthesis and biomass formation. Cultivations were carried out by supplementing $15 \mathrm{mM}$ of coumarate, ferulate or caffeate together with $25 \mathrm{mM}$ of acetate. The WP strain utilized both coumarate and ferulate efficiently, although product formation measured as luminescence signal was higher from coumarate (Figures $2 \mathrm{~A}, 2 \mathrm{~B}$ and $2 \mathrm{C}$ ). Biomass, on the other hand, was produced rather similarly between these two compounds. In both cases, growth ceased within 20 hours followed by a rapid drop in the luminescence signal (Figure 2B). Caffeate supplementation, on the other hand, revealed possible inhibition by the compound seen as prolonged lag phase, and low luminescence signal and biomass formation (Figures 2A, 2B and 2C). However, ADP1 wild type has previously been shown to consume caffeate at a lower concentration of $10 \mathrm{mM}$ (Salmela et al., 2018b).

The optical density, luminescence and fluorescence profiles of the AP strain show similar substrate preferences as with the WP strain; coumarate and ferulate were efficiently utilized for simultaneous biomass and alkane production (Figures 3A, 3B, 3C and 3D). Although caffeate supplementation yielded somewhat better growth for the AP strain than with the WP strain (Figure 3A), low luminescence and fluorescence signals indicate inefficient direction of substrate for the product 
225 formation (Figures 3c and 3D). Estimated by the fluorescence signal, alkane production was highest

226 with coumarate as the carbon source (Figure 3D). This correlates with the higher cumulative

227 luminescence obtained from coumarate-supplemented cultivations compared to the other carbon

228 sources ( $3 \mathrm{C})$. Furthermore, the cumulative luminescence signal produced by the AP strain from

229 coumarate was 11.5 fold higher than with the WP strain. The heterologous enzyme AAR is more

230 efficient in supplying aldehyde substrate for the bacterial luciferase LuxAB, which explains the higher

231 obtained luminescence signal (Lehtinen et al., 2017b; Lehtinen et al., 2018a). Thus, the architecture

232 and the comprising enzymes of a production pathway may have a significant role in determining the

233 production yield in the context of LDM utilization.

The biochemistry of the funnelling pathway in $A$. baylyi is similar to those of the other $\beta$-ketoadipate utilizing microorganism, such as Pseudomonas putida (Parke et al., 2000)(Harwood and Parales, 1996). In both microorganisms, LDMs such as coumarate, ferulate and caffeate are converted

237 through the protocatechuate branch to single intermediates. The biocatalytic efficiencies of the first enzymatic steps of this upper funneling pathway may vary between the carbon sources. For example, muconate production by a genetically engineered $P$. putida KT2440-CJ102 yielded slightly higher conversion rates for coumarate than ferulate (Johnson et al., 2017). The structural differences between the studied LDMs might explain why coumarate is favored over ferulate and caffeate. Ferulate requires demethylation of the aromatic structure, whereas the aromatic ring structure of coumarate can be directly hydroxylated to the central intermediate protocatechuate. 4HBA and vanillate are produced as overflow metabolites from coumarate and ferulate (Parke and

245 Ornston, 2003), and although not yet fully elucidated in A. baylyi, the transport efficiencies of these compounds may also vary. Although real lignin-derived streams are more complex in their composition than these model compounds, studies on individual compounds reveal valuable details about the host metabolism for future process design. 
250 Microorganisms with high tolerance towards inhibitory compounds, such as aromatics and acetate,

251 are attractive candidates for the possible upgrading of lignin-derived molecules to value added

252 products. Acetate has been associated as a part of hardwood lignins (Lu and Ralph, 2010), as well as

253 a residual components produced by lignocellulose treatment processes (Jönsson and Martín, 2016).

254 Previously, A. baylyi has been shown to tolerate and utilize acetate as a sole carbon source at

255 concentrations as high as $200 \mathrm{mM}$ (Lehtinen et al., 2017b). Complex substrate regulation systems in

256 A. baylyi include global regulators causing, for example, carbon-catabolite repression, as well as

257 vertical and horizontal regulation by intermediates (Bleichrodt et al., 2010). For example, A. baylyi

258 ADP1 prefers acetate as a carbon sources over the aromatic compounds (Zimmermann et al., 2009).

259 Consequently, this regulation may result in sequential use of the carbon sources, slower conversion

260 rates, and eventually in inefficient product formation and substrate utilization. On the other hand,

261 reactions occurring at the $\beta$-ketoadipate pathway are oxygenase mediated, and do not provide ATP

262 reserves (Ornston and Stanier, 1966). Thus, an alternative carbon source typical for lignin processes,

263 such as acetate, provides means to accelerate cellular growth.

264 To determine the effect of acetate on coumarate utilization and to elaborate the inhibitory effect of

265 using a mixture of coumarate and acetate, the WP strain was cultured at different concentrations of

266 acetate (25-90 $\mathrm{mM})$ and coumarate (15-50 mM). Coumarate was chosen as a model compound

267 based on the results obtained from the product synthesis experiments with different LDM-

268 representatives. With acetate and coumarate concentrations up to $55 \mathrm{mM}$ and $30 \mathrm{mM}$, respectively,

269 efficient formation of biomass and products was observed, whereas with $75 \mathrm{mM}$ acetate and $45 \mathrm{mM}$

270 coumarate, cell viability was severely impaired (Figures 4, 4B). Furthermore, higher substrate

271 concentrations promoted more diauxic growth. In addition to substrate inhibition, elevated

272 concentrations of the metabolic key intermediates, such as carboxymuconate and its precursor

273 protocatechuate, are toxic to cells (Parke et al., 2000). Towards the end of the experiment, subtle

274 growth was also observed with the cultures supplemented with $90 \mathrm{mM}$ acetate and $50 \mathrm{mM}$ 
concentrations allow for faster and more efficient growth and product formation. For comparison, glucose grown P. putida KT2240 and E. coli MG1655 were inhibited ( $33 \%$ reduction in growth rate) by $61 \mathrm{mM}$ and $30.4 \mathrm{mM}$ of coumarate or $65.6 \mathrm{mM}$ and $91.4 \mathrm{mM}$ of acetate, respectively, when supplemented individually Calero et al. (2017). To obtain higher tolerance towards inhibitory substrates, strain optimization could be applied through adaptation and laboratory evolution (Dragosits and Mattanovich, 2013) or by genetic engineering. For example, Benndorf et al. (2001) showed that by inducing $A$. calcoaceticus $69-\mathrm{V}$ (A. baylyi previously referred to as $A$. calcoaceticus) with $14 \mathrm{mM}$ of phenols or catechols heat shock proteins were produced to increase tolerance towards oxidative stress. Kohlstedt et al. 2018 achieved a $20 \%$ higher tolerance towards catechols in P. putida by expressing native cat $\mathrm{A}$ and cat $\mathrm{A} 2$ genes under the same cat $\mathrm{A}$ promoter.

\section{Wax ester and alkane production from coumarate in batch cultures}

Based on the previous experiments, coumarate was used as the carbon source for product level investigation of wax esters and alkane accumulation from LDMs. Products were analyzed after 8, 12 and $24 \mathrm{~h}$ from $50 \mathrm{ml}$ cultivations supplemented with $25 \mathrm{mM}$ of acetate and $15 \mathrm{mM}$ of coumarate. Casein amino acids or $25 \mathrm{mM}$ of acetate and casein amino acids supplementation were used as control cultivations. As hypothesized, the WP strain was able to produce wax esters from coumarate (Figure 5, Table 1). Both acetate and coumarate were consumed rather simultaneously (Table 1) in the studied conditions, although $6.4 \pm 0.6 \mathrm{mM}$ 4-HBA had accumulated at the time point of $12 \mathrm{~h}$ as an intermediate from coumarate conversion. Experimental data on substrate preferences of $A$. baylyi wild type (Supplementary Figure S3) show that 4-HBA -the overflow metabolite from coumarate- is depleted from the media mainly after all other carbon sources have been depleted. Similarly, after 24 hours, 4-HBA was depleted by the WP strain resulting in a significantly higher biomass compared to the control cultivations. Cell death caused by carbon depletion was observed as decreased $\mathrm{OD}_{600}$ after 24 hours. The wax ester content increased during the first $12 \mathrm{~h}$, whereas after $24 \mathrm{~h}$, a weaker wax ester band on TLC was observed (Figure 5). In the acetate control cultivations, the wax esters were depleted already within $12 \mathrm{~h}$, whereas in the casein amino acid control cultivations wax esters 
302

303

304

305

306

307 were not detected. The depletion of wax esters in carbon deficient conditions has been recorded for example by Fixter et al. (1986) and Santala et al. (2011). Therefore, using substrates such as LDM pose a challenge for wax ester production and preservation due to their inhibitory effects at elevated concentrations. Unspecific strategies, such as adaptive laboratory evolution could allow the use of higher substrate concentrations, whereas metabolic engineering can provide means to circumvent the challenges related storage compound degradation (Lehtinen et al., 2017b).

In the AP strain, the gene responsible for alkane degradation has been knocked-out, resulting in an intracellular product that is non-degradable by the host metabolism. Here, we demonstrated that the AP strain produced alkanes from coumarate in a 12-hour batch cultivation. In the culture, acetate and coumarate were depleted within 8 hours, although $11 \mathrm{mM}$ of 4-HBA had accumulated during this time (Table 2). Already at this time point, heptadecane was detected (Figure 6). After 12 hours, 4-HBA was consumed and a significant increase to $169 \mu \mathrm{g} / \mathrm{L}$ of heptadecane was observed, whereas production from acetate and casein amino acids control and casein amino acid control was negligible, $16.8 \mu \mathrm{g} / \mathrm{L}$ and $12.0 \mu \mathrm{g} / \mathrm{L}$ respectively. After 24 hours, an intriguing phenomenon was observed when analyzing the alkanes: although the heptadecane concentration slightly decreased towards the end of the experiments, the amount of 8-heptadecene increased indicating that double bond conversion may have taken place inside the cells (Supplementary Figure S3). Furthermore, it is possible that some of the alkanes were lost in the supernatant due to carbon starvation and cell lysis. Heptadecane was produced modestly in the batch experiments: the $\mathrm{C} / \mathrm{C}$ yield from acetate and coumarate was slightly higher $(0.006 \%)$ when compared to our previous studies $(0.005 \%)$ using acetate as a sole substrate (Lehtinen et al., 2018b). Furthermore, the heptadecane yield from consumed coumarate was estimated to be $62.3 \mu \mathrm{g} / \mathrm{g}$. It should be noted that coumarate serves as a substrate for both biomass formation and product synthesis. For efficient direction of carbon to product, decoupling of product and biomass synthesis could be achieved by metabolic engineering (Santala et al., 2018). 


\section{Wax ester production from coumarate in bioreactor}

328 The WP strain produced wax esters from coumarate effectively in the $50 \mathrm{ml}$ batch studies. Thus, a

329 bioreactor experiment was conducted to elucidate the dynamics of wax ester accumulation from

330 coumarate. One of the challenges in maintaining reactions favorable towards product formation

331 when utilizing LDMs, such as coumarate, is caused by substrate inhibition. With low substrate doses,

332 swift carbon depletion is followed by rapid wax ester degradation. Interestingly, in our shake-flask

333 cultivations wax esters were detected even after prolonged carbon starvation. As the ring cleavage

334 of aromatic compounds by bacteria is an oxygen intensive process (Fuchs et al., 2011), we tested

335 whether the premature wax ester degradation could be avoided by restricting the metabolic activity

336 of the cell by limiting the oxygen supply in the bioreactor. Furthermore, we fed the coumarate

337 gradually in the bioreactor to study the effect of substrate concentration for the wax ester

338 production.

339 An initial total volume of $750 \mathrm{ml}$ medium was supplemented with $25 \mathrm{mM}$ of acetate and $15 \mathrm{mM}$ of

340 coumarate and inoculated with the WP strain. After substrate depletion, the reactor was re-

341 supplemented twice with elevated coumarate concentrations ( $25 \mathrm{mM}$ and $34 \mathrm{mM})$. Automated

342 supply of pure oxygen ( $1 \mathrm{vvm}$ ) was initiated when the $\mathrm{pO}_{2}$ decreased below $20 \%$. Regardless of the

343 additional $\mathrm{O}_{2}$ supply, the $\mathrm{pO}_{2}$ remained at $0 \%$ throughout coumarate utlization and spiked only at

344 substrate depletion (Figure 7). Both acetate and coumarate were consumed during the first 10 hours

345 of cultivation and wax esters accumulated at time points of 7, 8 and 9 hours (Figure 7) up to 26

$346 \mathrm{mg} / \mathrm{L}$. However, after carbon depletion, the wax esters were consumed rapidly within 60 minutes at

347 time point of 10 hours.

348 To study the effect of oxygen in wax ester degradation, the pure oxygen supply was shut off at $12 \mathrm{~h}$

349 and the reactor was aerated only with an airflow at a rate of $1 \mathrm{vvm}$. At this point, $25 \mathrm{mM}$ of

350 coumarate was also added to the reactor. After $12 \mathrm{~h}$ cultivation in these conditions, the

351 supplemented coumarate had been depleted and cell growth observed, though wax esters were not 
detected (Figure 7). The automated $\mathrm{O}_{2}$ supply was re-initiated and an elevated concentration of coumarate was added to the reactor. Re-supplementation with an increased coumarate concentration $(34 \mathrm{mM})$ resulted in rapid utilization of coumarate for biomass and wax esters between the time points of $27-37 \mathrm{~h}$. Small amounts of 4-HBA accumulated during these 10 hours. In addition, a peak in acetate accumulation (14 mM) was observed at time point of 29 hours. At the end of the experiment at 37 hours, the obtained biomass was $5.0 \mathrm{~g} / \mathrm{L}$. The $\mathrm{pH}$ of the cultivation varied between $\mathrm{pH}$ 6.1-8.3 until finally reaching 8.7 at the end of cultivation. Intracellular wax esters were produced up to $221 \mathrm{mg} / \mathrm{L}$ at the end of the bioreactor experiment and a yield of $40 \mathrm{mg}_{\text {wax }}$ ester/gcoumarate was obtained between time points $27-37$. The yield is higher than previously obtained results for $A$. baylyi wild type $\left(14-20 \mathrm{mg} \mathrm{g}_{\text {wax ester }} / \mathrm{g}_{\text {substrate }}\right)$ when using glucose or acetate as a substrate (Lehtinen et al., 2018b)(Santala et al., 2018) and implicates coumarate as a potential carbon source for wax ester production.

\section{Conclusions}

The ability of microorganisms to produce industrially relevant compounds from low cost substrates, as well as the flexibility of modifying the cellular systems to produce non-native products, pave the way for a more sustainable biobased economy. Here, we showed that LDMs can be used for long chain alkyl ester $\left(\mathrm{C}_{32}-\mathrm{C}_{34}\right)$ production - the naturally accumulated storage compounds of $A$. baylyias well as for the production of drop-in fuel components in the form of long chain alkanes $\left(C_{17}\right)$ produced by a synthetic pathway. In addition, we observed that the chemical structure of the studied LDMs affect biomass and product synthesis, coumarate being the most propitious for product and biomass formation. Thus, the choice of biomass and pre-treatment methods could be adjusted to generate LDMs that are optimal for production.

\section{Conflicts of interest}

There are no conflicts to declare. 
376

377

378

379

380

381

382

\section{REFERENCES}

Abdelkafi F, Ammar H, Rousseau B, Tessier M, El Gharbi R, Fradet A. 2011. Structural analysis of alfa grass (Stipa tenacissima L.) lignin obtained by acetic acid/formic acid delignification. Biomacromolecules 12:3895-3902.

Adeboye PT, Bettiga M, Olsson L. 2014. The chemical nature of phenolic compounds determines their toxicity and induces distinct physiological responses in Saccharomyces cerevisiae in lignocellulose hydrolysates. AMB Express 4:46.

Alvarez HM, Steinbüchel A. 2003. Triacylglycerols in prokaryotic microorganisms. Appl. Microbiol.

Benndorf D, Loffhagen N, Babel W. 2001. Protein synthesis patterns in Acinetobacter calcoaceticus induced by phenol and catechol show specificities of responses to chemostress. FEMS Microbiol. Lett. 200:247-252.

de Berardinis V, Vallenet D, Castelli V, Besnard M, Pinet A, Cruaud C, Samair S, Lechaplais C, Gyapay G, Richez C, Durot M, Kreimeyer A, Le Fèvre F, Schächter V, Pezo V, Döring V, Scarpelli C, Médigue C, Cohen GN, Marlière $P$, Salanoubat $M$, Weissenbach J. 2008. A complete collection of single-gene deletion mutants of Acinetobacter baylyi ADP1. Mol. Syst. Biol. 4.

Bleichrodt FS, Fischer R, Gerischer UC. 2010. The $\beta$-ketoadipate pathway of Acinetobacter baylyi undergoes carbon catabolite repression, cross-regulation and vertical regulation, and is affected by Crc. Microbiology 156:1313-1322.

Calero P, Jensen SI, Bojanovič K, Lennen RM, Koza A, Nielsen AT. 2018. Genome-wide identification of tolerance mechanisms toward p-coumaric acid in Pseudomonas putida. Biotechnol. Bioeng. 115:762-774.

Cao Y-X, Xiao W-H, Zhang J-L, Xie Z-X, Ding M-Z, Yuan Y-J. 2016. Heterologous biosynthesis and manipulation of alkanes in Escherichia coli. Metab. Eng. 38:19-28.

Clark JH, Budarin V, Deswarte FEl, Hardy JJE, Kerton FM, Hunt AJ, Luque R, Macquarrie DJ, Milkowski K, Rodriguez A, Samuel O, Tavener SJ, White RJ, Wilson AJ. 2006. Green chemistry and the biorefinery: a partnership for a sustainable future. Green Chem. 8:853.

Constant S, Wienk HL, Frissen AE, Peinder P de, Boelens R, van Es DS, Grisel RJH, Weckhuysen BM, Huijgen WJJ, Gosselink RJA, Bruijnincx PCA. 2016. New insights into the structure and composition of technical lignins: a comparative characterisation study. Green Chem. 18:2651-2665.

Dewitt S, Ervin JL, Howes-Orchison D, Dalietos D, Neidleman SL, Geigert J. 1982. Saturated and Unsaturated Wax Esters Produced by Acinetobacter sp. HO1-N Grown on C 16 -C 20 n-Alkanes. J. Am. Oil Chem. Soc. 59:69-74.

Dragosits M, Mattanovich D. 2013. Adaptive laboratory evolution - principles and applications for biotechnology. Microb. Cell Fact. 12:64.

Elliott KT, Neidle EL. 2011. Acinetobacter baylyi ADP1: Transforming the choice of model organism. IUBMB Life.

Elshahed MS. 2010. Microbiological aspects of biofuel production: Current status and future directions. J. Adv. Res. 1:103-111.

Fatma Z, Hartman H, Poolman MG, Fell DA, Srivastava S, Shakeel T, Yazdani SS. 2018. Model-assisted metabolic engineering of Escherichia coli for long chain alkane and alcohol production. Metab. Eng. $46: 1-12$. 
417 Fischer R, Bleichrodt FS, Gerischer UC. 2008. Aromatic degradative pathways in Acinetobacter baylyi

418 underlie carbon catabolite repression. Microbiology 154:3095-3103.

419 FitzPatrick M, Champagne P, Cunningham MF, Whitney RA. 2010. A biorefinery processing

420 perspective: Treatment of lignocellulosic materials for the production of value-added products.

421 Bioresour. Technol. 101:8915-8922.

422 Fixter LM, Nagi MN, Mccormack JG, Fewson CA. 1986. Structure, Distribution and Function of Wax

423 Esters in Acinetobacter calcoaceticus. Microbiology 132:3147-3157.

424 Freed E, Fenster J, Smolinski SL, Walker J, Henard CA, Gill R, Eckert CA. 2018. Building a genome

425 engineering toolbox in nonmodel prokaryotic microbes. Biotechnol. Bioeng. 115:2120-2138.

426 Fuchs G, Boll M, Heider J. 2011. Microbial degradation of aromatic compounds - from one strategy

427 to four. Nat. Rev. Microbiol. 9:803-816.

428 Hartmans, S., Smits, J., Werf, M. v. d., Volkering, F., and Bont, J. d. (1989). Metabolism of styrene

429 oxide and 2-phenyl ethanol in the styrene degrading Xanthobacter strain 124X. Appl environ

430 Microbiol 55, 2850-2855

431 Harwood CS, Parales RE. 1996. The $\beta$-ketoadipate pathway and the biology of self-identity. Annu.

432 Rev. Microbiol. 50:553-590.

433 Johnson CW, Abraham PE, Linger JG, Khanna P, Hettich RL, Beckham GT. 2017. Eliminating a global

434 regulator of carbon catabolite repression enhances the conversion of aromatic lignin monomers to

435 muconate in Pseudomonas putida KT2440. Metab. Eng. Commun. 5:19-25.

436 Jönsson L, Martín C. 2016. Pretreatment of lignocellulose: Formation of inhibitory by-products and 437 strategies for minimizing their effects. Bioresour. Technol. 199:103-112.

438 Kalscheuer R, Steinbüchel A. 2003. A novel bifunctional wax ester synthase/acyl-CoA:diacylglycerol 439 acyltransferase mediates wax ester and triacylglycerol biosynthesis in Acinetobacter calcoaceticus 440 ADP1. J. Biol. Chem. 278:8075-82.

441 Kannisto M, Aho T, Karp M, Santala V. 2014. Metabolic Engineering of Acinetobacter baylyi ADP1 for Improved Growth on Gluconate and Glucose. Appl. Environ. Microbiol. 80:7021-7027.

Karp EM, Nimlos CT, Deutch S, Salvachúa D, Cywar RM, Beckham GT. 2016. Quantification of acidic compounds in complex biomass-derived streams. Green Chem. 18:4750-4760.

Katahira R, Mittal A, McKinney K, Chen X, Tucker MP, Johnson DK, Beckham GT. 2016. Base-

447 Kohlstedt M, Starck S, Barton N, Stolzenberger J, Selzer M, Mehlmann K, Schneider R, Pleissner D,

448 Rinkel J, Dickschat JS, Venus J, B.J.H. van Duuren J, Wittmann C. 2018. From lignin to nylon: Cascaded 449 chemical and biochemical conversion using metabolically engineered Pseudomonas putida. Metab.

450 Eng. 47:279-293.

451 Kosa M, Ragauskas AJ. 2012. Bioconversion of lignin model compounds with oleaginous Rhodococci.

452 Appl. Microbiol. Biotechnol. 93:891-900.

453 Lehtinen T, Efimova E, Santala S, Santala V. 2018a. Improved fatty aldehyde and wax ester 454 production by overexpression of fatty acyl-CoA reductases. Microb. Cell Fact. 17:19.

455 Lehtinen T, Efimova E, Tremblay PL, Santala S, Zhang T, Santala V. 2017a. Production of long chain 456 alkyl esters from carbon dioxide and electricity by a two-stage bacterial process. Bioresour. Technol. $457 \quad 243: 30-36$. 
458 Lehtinen T, Santala V, Santala S. 2017b. Twin-layer biosensor for real-time monitoring of alkane

459 metabolism. FEMS Microbiol. Lett. 364.

460 Lehtinen T, Virtanen H, Santala S, Santala V. 2018b. Production of alkanes from CO2 by engineered

461 bacteria. Biotechnol. Biofuels 11:228.

462 Li M, Foster C, Kelkar S, Pu Y, Holmes D, Ragauskas A, Saffron CM, Hodge DB. 2012. Structural

463 characterization of alkaline hydrogen peroxide pretreated grasses exhibiting diverse lignin

464 phenotypes. Biotechnol. Biofuels 5:38.

465 Linger JG, Vardon DR, Guarnieri MT, Karp EM, Hunsinger GB, Franden MA, Johnson CW, Chupka G, 466 Strathmann TJ, Pienkos PT, Beckham GT. 2014. Lignin valorization through integrated biological

467 funneling and chemical catalysis. Proc. Natl. Acad. Sci. 111:12013-12018.

468 Lu F, Ralph J. 2010. Lignin. In: Cereal Straw as a Resource for Sustainable Biomaterials and Biofuels.

469 Elsevier, pp. 169-207.

470 Metzgar D. 2004. Acinetobacter sp. ADP1: an ideal model organism for genetic analysis and genome 471 engineering. Nucleic Acids Res. 32:5780-5790.

472 Nielsen DR, Leonard E, Yoon SH, Tseng HC, Yuan C, Prather KLJ. 2009. Engineering alternative

473 butanol production platforms in heterologous bacteria. Metab. Eng. 11:262-273.

474 Ornston LN. 1966. The conversion of catechol and protocatechuate to $\beta$-ketoadipate by

475 Pseudomonas putida. II. Enzymes of the protocatechuate pathway. J. Biol. Chem. 241:3787-94.

476 Ornston LN, Stanier RY. 1966. The conversion of catechol and protocatechuate to beta-ketoadipate

477 by Pseudomonas putida. J. Biol. Chem. 241:3776-86.

478 Palmqvist E, Hahn-Hägerdal B. 2000. Fermentation of lignocellulosic hydrolysates. II: Inhibitors and

479 mechanisms of inhibition. Bioresour. Technol. 74:25-33.

480 Parke D, D'Argenio DA, Ornston LN. 2000. Bacteria are not what they eat: that is why they are so 481 diverse. J. Bacteriol. 182:257-63.

482 Parke D, Ornston N. 2003. Hydroxycinnamate (hca) catabolic genes from Acinetobacter sp. strain $483 \mathrm{ADP} 1$ are repressed by $\mathrm{HcaR}$ and are induced by hydroxycinnamoyl-coenzyme A thioesters. Appl. 484 Environ. Microbiol. 69:5398-5409.

485 Peralta-Yahya PP, Zhang F, del Cardayre SB, Keasling JD. 2012. Microbial engineering for the 486 production of advanced biofuels. Nature 488:320-328.

487 Raj A, Krishna Reddy MM, Chandra R. 2007. Identification of low molecular weight aromatic 488 compounds by gas chromatography-mass spectrometry (GC-MS) from kraft lignin degradation by 489 three Bacillus sp. Int. Biodeterior. Biodegrad. 59:292-296.

490 Reiser S, Somerville C. 1997. Isolation of mutants of Acinetobacter calcoaceticus deficient in wax 491 ester synthesis and complementation of one mutation with a gene encoding a fatty acyl coenzyme A 492 reductase. J. Bacteriol.

493 Rumbold K, van Buijsen HJ, Overkamp KM, van Groenestijn JW, Punt PJ, Werf M. 2009. Microbial 494 production host selection for converting second-generation feedstocks into bioproducts. Microb. 495 Cell Fact. 8:64.

496 Salmela M, Lehtinen T, Efimova E, Santala S, Mangayil R. 2018a. Metabolic pairing of aerobic and 497 anaerobic production in a one-pot batch cultivation. Biotechnol. Biofuels 11:187.

498 Salmela M, Sanmark H, Efimova E, Efimov A, Hytönen VP, Lamminmäki U, Santala S, Santala V. 
499 2018b. Molecular tools for selective recovery and detection of lignin-derived molecules. Green

500 Chem.

501 Santala S, Efimova E, Karp M, Santala V. 2011. Real-Time monitoring of intracellular wax ester

502 metabolism. Microb. Cell Fact. 10:75.

503 Santala S, Efimova E, Koskinen P, Karp MT, Santala V. 2014. Rewiring the Wax Ester Production

504 Pathway of Acinetobacter baylyi ADP1. ACS Synth. Biol. 3:145-151.

505 Santala S, Efimova E, Santala V. 2018. Dynamic decoupling of biomass and wax ester biosynthesis in 506 Acinetobacter baylyi by an autonomously regulated switch. Metab. Eng. Commun. 7:e00078.

507 Schirmer A, Rude MA, Li X, Popova E, del Cardayre SB. 2010. Microbial biosynthesis of alkanes.

508 Science 329:559-62.

509 Steen EJ, Kang Y, Bokinsky G, Hu Z, Schirmer A, McClure A, del Cardayre SB, Keasling JD. 2010.

510 Microbial production of fatty-acid-derived fuels and chemicals from plant biomass. Nature 463:559-

511562.

512 Stöveken T, Steinbüchel A. 2008. Bacterial Acyltransferases as an Alternative for Lipase-Catalyzed

513 Acylation for the Production of Oleochemicals and Fuels. Angew. Chemie Int. Ed. 47:3688-3694.

514 Sun RC, Sun XF, Zhang SH. 2001. Quantitative determination of hydroxycinnamic acids in wheat, rice, 515 rye, and barley straws, maize stems, oil palm frond fiber, and fast-growing poplar wood. J. Agric.

516 Food Chem. 49:5122-5129.

517 Sun S, Wen J, Sun S, Sun R-C. 2015. Systematic evaluation of the degraded products evolved from 518 the hydrothermal pretreatment of sweet sorghum stems. Biotechnol. Biofuels 8:37.

519 Uthoff S, Stöveken T. 2005. Thio wax ester biosynthesis utilizing the unspecific bifunctional wax ester 520 synthase/acyl coenzyme A: diacylglycerol acyltransferase of Acinetobacter sp. strain ADP1. Appl. ....

521 Wells T, Ragauskas AJ. 2012. Biotechnological opportunities with the $\beta$-ketoadipate pathway. Trends 522 Biotechnol.

523 Zimmermann T, Sorg T, Siehler SY, Gerischer U. 2009. Role of Acinetobacter baylyi crc in catabolite 524 repression of enzymes for aromatic compound catabolism. J. Bacteriol. 191:2834-2842. 
527 Table 1: Carbon source depletion presented as consumed substrate per supplemented substrate (\%)

528 and growth as $\mathrm{OD}_{600}$ by the WP strain measured at three time points $(8,12$ and $24 \mathrm{~h})$. Batches were

supplement either with acetate, coumarate and casein amino acids, acetate and casein amino acids

530

or casein amino acids. Results are presented for three biological replicates with standard deviation

marked as \pm .

\begin{tabular}{|c|c|c|c|c|c|c|}
\hline \multirow{2}{*}{ Time, h } & \multicolumn{3}{|c|}{$\begin{array}{l}25 \mathrm{mM} \text { acetate, } 15 \mathrm{mM} \text { coumarate and } \\
0.2 \% \text { casein amino acids }\end{array}$} & \multicolumn{2}{|c|}{$\begin{array}{l}25 \mathrm{mM} \text { acetate and } 0.2 \% \\
\text { casein amino acids }\end{array}$} & \multirow{2}{*}{$\begin{array}{l}0.2 \% \text { casein } \\
\text { amino acids } \\
\text { OD }\end{array}$} \\
\hline & $\begin{array}{l}\text { Coumarate } \\
\text { consumed, \% }\end{array}$ & $\begin{array}{l}\text { Acetate } \\
\text { consumed, \% }\end{array}$ & OD & $\begin{array}{l}\text { Acetate } \\
\text { consumed, \% }\end{array}$ & OD & \\
\hline 8 & $28.7 \pm 3.5$ & $45.0 \pm 3.5$ & $1.60 \pm 0.10$ & $88 \pm 14$ & $1.49 \pm 0.27$ & $0.16 \pm 0.03$ \\
\hline 12 & 100.0 & 100.0 & $3.43 \pm 1.81$ & 100 & $1.45 \pm 0.08$ & $0.19 \pm 0.02$ \\
\hline 24 & 100.0 & 100.0 & $2.01 \pm 0.17$ & 100 & $0.66 \pm 0.34$ & $0.16 \pm 0.01$ \\
\hline
\end{tabular}

532

Table 2: Carbon source depletion presented as consumed substrate per supplemented substrate (\%)

\begin{tabular}{|c|c|c|c|c|c|c|}
\hline \multirow[b]{2}{*}{ Time, $\mathrm{h}$} & \multicolumn{3}{|c|}{$\begin{array}{l}25 \mathrm{mM} \text { acetate, } 15 \mathrm{mM} \text { coumarate and } \\
0.2 \% \text { casein amino acids }\end{array}$} & \multicolumn{2}{|c|}{$\begin{array}{l}25 \mathrm{mM} \text { acetate and } 0.2 \% \\
\text { casein amino acids }\end{array}$} & \multirow{2}{*}{$\begin{array}{l}0.2 \% \text { casein } \\
\text { amino acids } \\
\text { OD }\end{array}$} \\
\hline & $\begin{array}{l}\text { Coumarate } \\
\text { consumed, \% }\end{array}$ & $\begin{array}{l}\text { Acetate } \\
\text { consumed, \% }\end{array}$ & OD & $\begin{array}{l}\text { Acetate } \\
\text { consumed, \% }\end{array}$ & OD & \\
\hline 8 & $94.7 \pm 0.5$ & $82.8 \pm 4.35$ & $1.87 \pm 0.13$ & 100 & $1.43 \pm 0.0 .22$ & $0.12 \pm 0.03$ \\
\hline 12 & 100.0 & 100.0 & $2.51 \pm 0.17$ & 100 & $1.12 \pm 0.08$ & $0.11 \pm 0.02$ \\
\hline 24 & 100.0 & 100.0 & $2.10 \pm 0.06$ & 100 & $0.66 \pm 0.03$ & $0.16 \pm 0.01$ \\
\hline
\end{tabular}

539 Figure 1: The schematic presentation of carbon flow from lignin-derived monomers (LDMs;

540 coumarate, ferulate, caffeate) into products. The structurally analogous LDMs are first funneled into

541 a single intermediate, protocatechuate. After ring cleavage, the intermediate is metabolized by the

$542 \quad \beta$-ketoadipate pathway yielding acetyl-CoA and succinyl-CoA. From acetyl-CoA, two different

543 pathways for possible products (1A for wax esters, 1B for alkanes) are shown. In the native wax ester

544 synthesis pathway, first the fatty acyl-CoA is produced and then fatty alcohols via a fatty aldehyde 
545 intermediate. The fatty alcohols are esterified with fatty acyl-CoAs resulting in wax esters. In the

546 alkane producing strain, the natural fatty aldehyde reductase gene acr1 has been replaced with a

547 non-native reductase gene, aar. The fatty aldehydes produced by AAR are further converted to

548 alkanes by another heterologous enzyme, aldehyde deformylating oxygenase, ADO.

549 Figure 2. Biomass and product formation by the WP strain utilizing different LDMs as substrates.

550 Error bars have been left out from the A) and B) for clarity and are available in supplementary

551 material (Figure S1). A) Cell growth measured as optical density at $600 \mathrm{~nm}$ every 30 minutes. Carbon

552 sources used: $25 \mathrm{mM}$ acetate and $0.2 \%$ casein amino acids with $15 \mathrm{mM}$ coumarate (closed square),

553 ferulate (open circle) or caffeate (closed circle) supplementation. Control cultivations supplemented

554 with $25 \mathrm{mM}$ acetate and casein amino acids (cross) or casein amino acids (star). The results are the

555 average of three biological replicates. B) Real-time luminescence signal representing the internal

556 aldehyde (wax ester precursor) formation measured every 30 minutes. The results are the average

557 of three biological replicates. C) Cumulative luminescence signals representing relative product

558 formation from the different LDMs. The results are the average of three biological replicates and

559 error bars represent standard deviation.

560 Figure 3. Biomass and product formation by the AP strain utilizing different LDMs as substrates.

561 Error bars have been left out from the A) and B) for clarity and are available in supplementary

562 material (Figure S1). A) Cell growth measured as optical density at $600 \mathrm{~nm}$ every 30 minutes. Carbon

563 sources used: $25 \mathrm{mM}$ acetate and $0.2 \%$ casein amino acids with $15 \mathrm{mM}$ coumarate (closed square),

564 ferulate (open circle) or caffeate (closed circle) supplementation. Control cultivations supplemented

565 with $25 \mathrm{mM}$ acetate and casein amino acids (cross) or casein amino acids (star). The results are the

566 average of three biological replicates. B) Real-time luminescence signal representing the internal

567 aldehyde (alkane precursor) formation measured every 30 minutes. The results are the average of

568 three biological replicates. C) Cumulative luminescence signals representing relative product

569 formation from the different LDMs. The results are the average of three biological replicates and 
570 error bars represent standard deviation. C) Cumulative luminescence signals representing relative

571 product formation from the different LDMs. The results are the average of three biological replicates

572 and error bars represent standard deviation. D) Normalized fluorescence signals

573 (fluorescence/ $/ \mathrm{D}_{600}$ ) representing alkane production from LDMs. The results are the average of

574 three biological replicates and error bars represent the standard deviation of the samples.

575 Figure 4: The effect of increasing acetate and coumarate concentrations on growth and aldehyde

576 formation by the WP strain cultivated for 48 hours. A) Growth profiles as optical density $\left(\mathrm{OD}_{600}\right)$

577 measured every 30 minutes. Substrate concentrations used: $25 \mathrm{mM}$ acetate and $15 \mathrm{mM}$ coumarate

578 (cross), $30 \mathrm{mM}$ acetate and $15 \mathrm{mM}$ coumarate (open circle), $50 \mathrm{mM}$ acetate and $25 \mathrm{mM}$ coumarate

579 (opens square) $55 \mathrm{mM}$ acetate and $30 \mathrm{~mm}$ coumarate (closed square), $75 \mathrm{mM}$ acetate and $40 \mathrm{mM}$

580 coumarate (open triangle) and $90 \mathrm{mM}$ acetate and $50 \mathrm{mM}$ coumarate (closed triangle). B)

581 Cumulative luminescence signal from the different carbon sources at the end of the experiment (48

582 h). Error bars represent the standard deviation of three biological replicates. Error bars have been

583 left out for clarity and are available in supplementary material (Figure S2).

584 Figure 5. Semi-quantitative TLC analysis of the wax esters produced by the WP strain at different

585 time points. Samples were grown on $25 \mathrm{mM}$ acetate, $15 \mathrm{mM}$ coumarate and $0.2 \%$ casein amino

586 acids (lanes 1, 2 and 3), $25 \mathrm{mM}$ acetate and $0.2 \%$ casein amino acids (lanes 4,5 and 6 ) or $0.2 \%$ casein

587 amino acids (lanes 7, 8 and 9). Lanes 0 and 10 represent the wax ester standard (Jojoba oil). Time

588 points for each sample ( $8 \mathrm{~h}, 12 \mathrm{~h}$ and $24 \mathrm{~h})$ are shown at the top of the figure.

Figure 6. Heptadecane production as $\mu \mathrm{g} / \mathrm{L}$ by the AP strain from $25 \mathrm{mM}$ coumarate, $15 \mathrm{mM}$ acetate and $0.2 \%$ casein amino acids (white columns), $25 \mathrm{mM}$ acetate and $0.2 \%$ casein amino acids (grey columns) and $0.2 \%$ casein amino acids (striped grey columns) at $8 \mathrm{~h}, 12 \mathrm{~h}$ and $24 \mathrm{~h}$. The error bars represent the standard deviation from three biological replicates.

Figure 7: Bioreactor experiment for wax ester accumulation by the WP strain. A) Substrate 
during 37 hours of cultivation. Initially, the reactor was supplemented only with acetate and

coumarate. At time points $10.5 \mathrm{~h}$ and $26.5 \mathrm{~h}$, the cultivations were re-supplemented with

coumarate. 4-HBA is produced as an intermediate of coumarate conversion. B) Wax ester titer as

$\mathrm{mg} / \mathrm{L}$ (columns), biomass formation as cell dry weight in $\mathrm{g} / \mathrm{L}$ (open circles), partial oxygen pressure as replicates.

Supplementary Figure S2. Optical densities from Figure 4 presented with error bars. Error bars represent the standard deviation from three biological replicates.

Supplementary Figure S3. A. baylyi wild type substrate consumption in a $50 \mathrm{ml}$ batch cultivation supplemented with $25 \mathrm{mM}$ acetate (black square) and $15 \mathrm{mM}$ coumarate (open square). 4-HBA (black diamond) accumulates as an overflow metabolite from coumarate conversion. Cell growth measured as $\mathrm{OD}_{600}$ (open circle). 
bioRxiv preprint doi: https://doi.org/10. 001/502468; this version posted Decephber 21, 2018. The copyright இolder for this preprint (which was not certified by peer review) is the author/funder, who has granted bioRxiv allicense to display the preprint in perpetuity. It is made available<smiles>OC/C=C/c1ccc(O)cc1</smiles>

Coumarate<smiles>COc1cc(C)nc(C(C)(C)C)c1O</smiles>

Ferulate

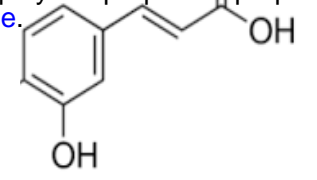

Caffeate<smiles>O=C(O)c1ccc(O)c(O)c1</smiles>

Protocatechuate<smiles>C=C[Tl]</smiles>

$\beta$-ketoadipate pathway

$1 \mathrm{~A}$

Acetyl-CoA, Succinyl-CoA

1B

$$
\begin{aligned}
& \text { Fatty } \\
& \text { acyl-CoA }
\end{aligned}
$$

Acr1

Fatty aldehyde

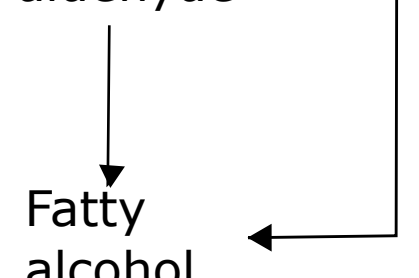

\section{Wax ester}
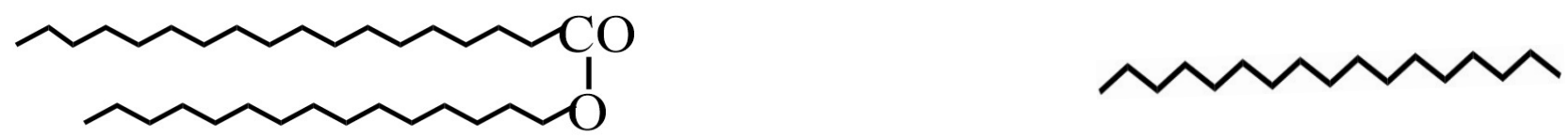

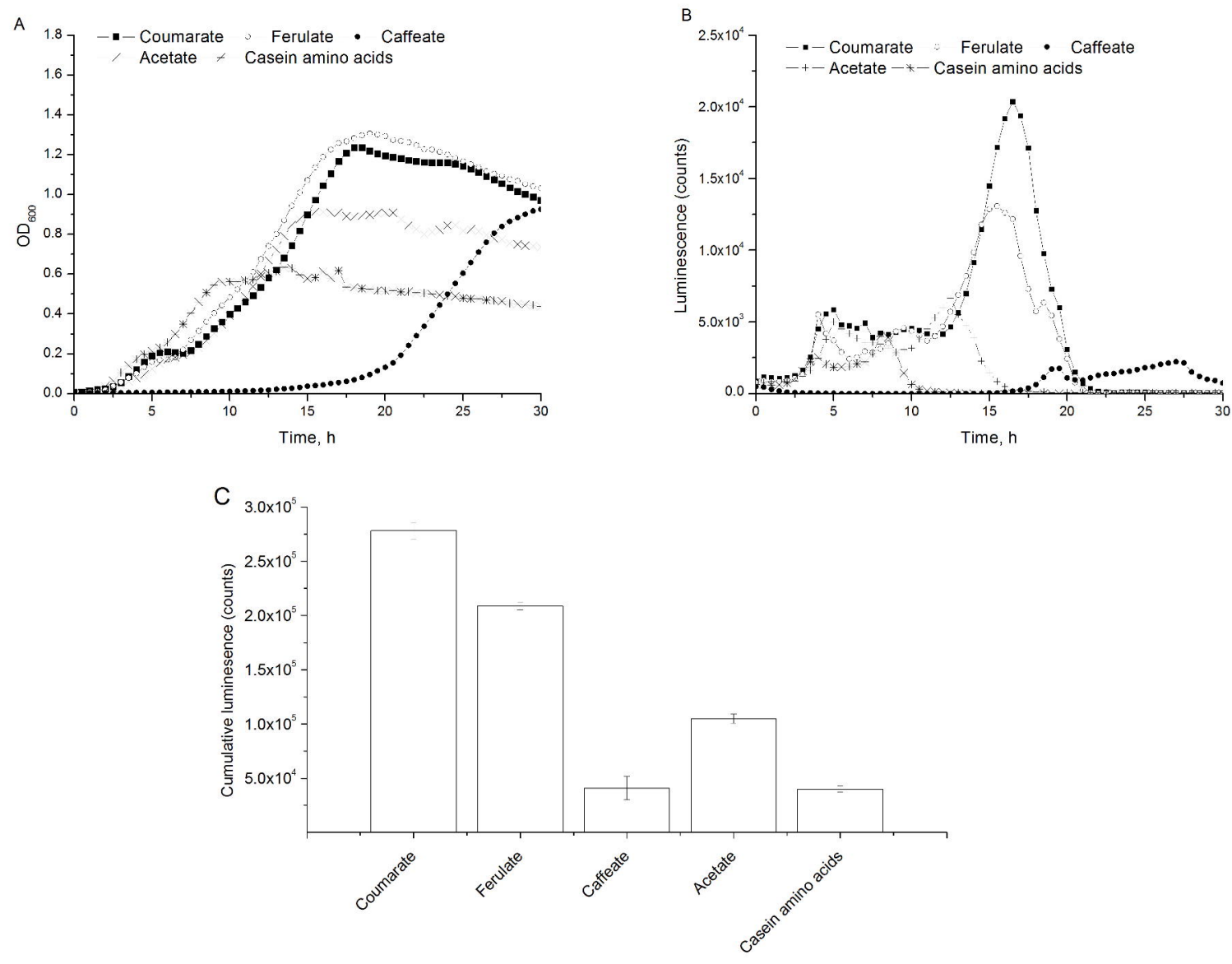
A
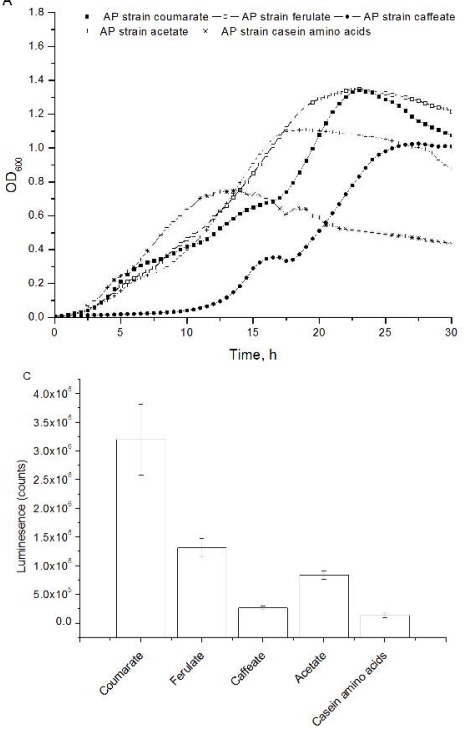
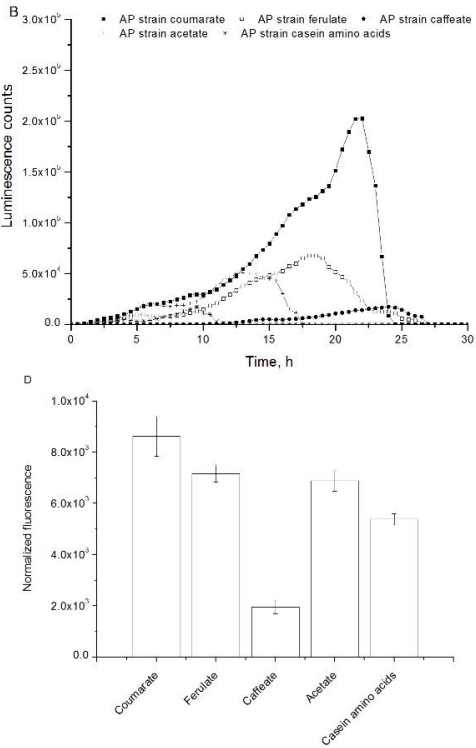


\author{
0 \\ 1 \\ 2 \\ 3
}

4

5

6 Acetate control
7 Casein amino acids control
10

WE standard 


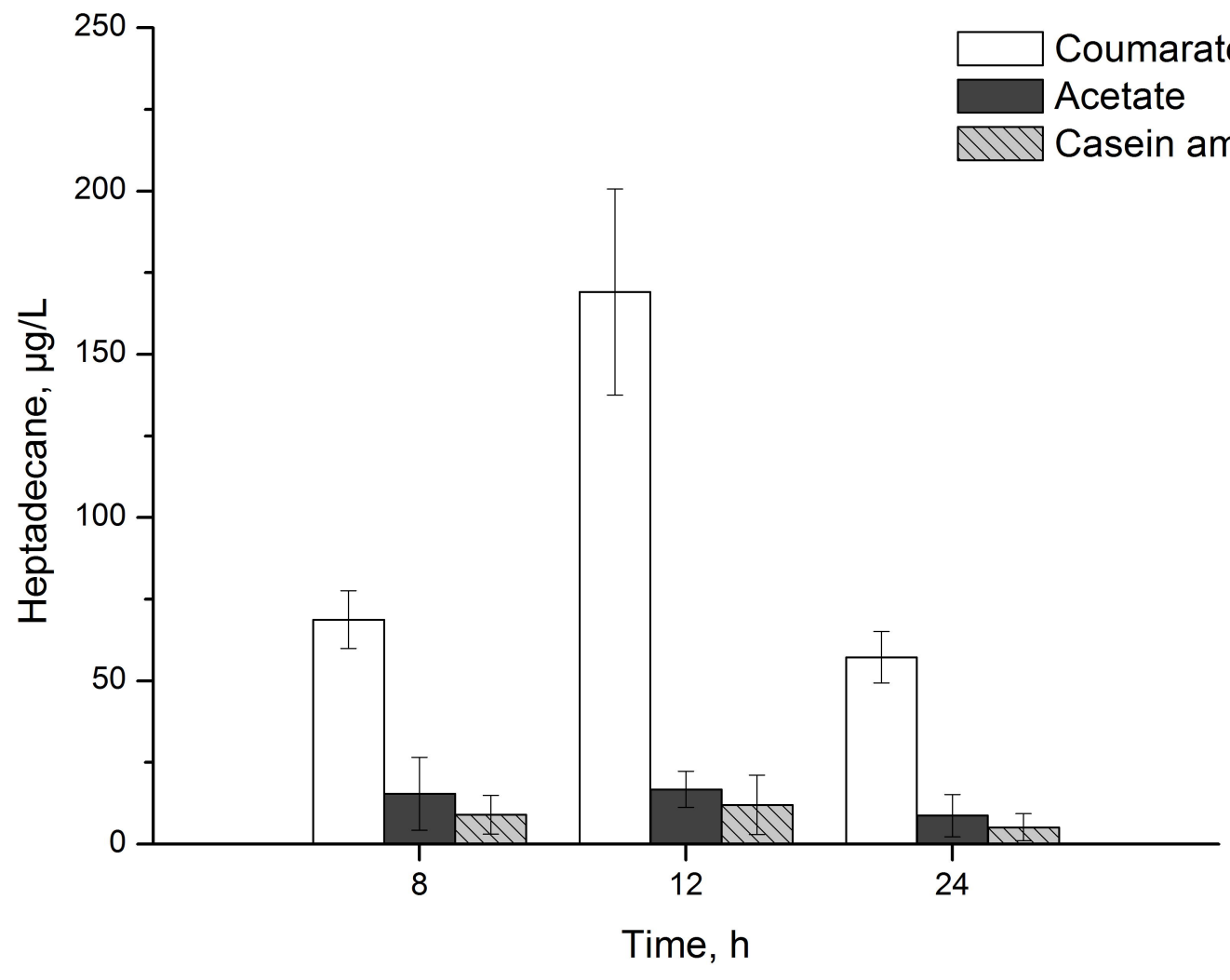


A

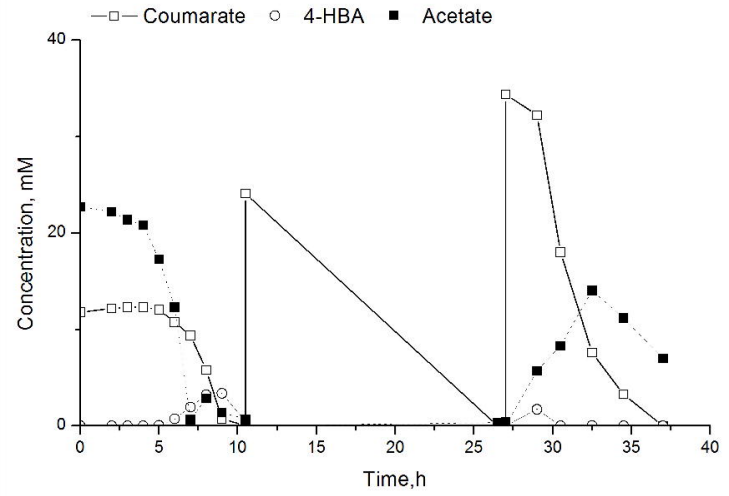

B

$\begin{array}{llll}-0-\text { Cell dry weight } \square \text { Wax esters } & \mathrm{pH} & \mathrm{pO} 2\end{array}$

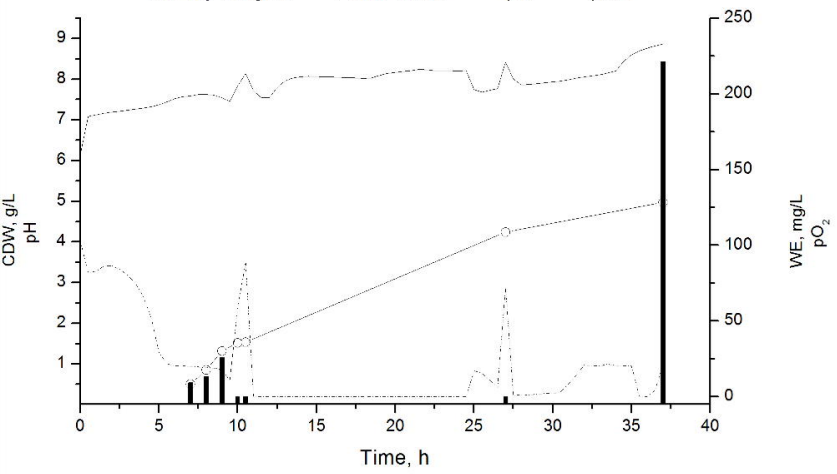

